University of Wollongong

Research Online

Faculty of Engineering and Information

Faculty of Engineering and Information

Sciences - Papers: Part A

Sciences

$1-1-2016$

Combined bearing and shear-out capacity of structural steel bolted connections

Lip H. Teh

University of Wollongong, Iteh@uow.edu.au

Mehmet Eren Uz

Adnan Menderes University, meuz@uow.edu.au

Follow this and additional works at: https://ro.uow.edu.au/eispapers

Part of the Engineering Commons, and the Science and Technology Studies Commons

Research Online is the open access institutional repository for the University of Wollongong. For further information contact the UOW Library: research-pubs@uow.edu.au 


\title{
Combined bearing and shear-out capacity of structural steel bolted connections
}

\begin{abstract}
This study is concerned with the strength limit state of serial bolted connections in structural steel plates. It points out that the ultimate load capacity of a serial bolted connection failing in combined bearing and shear-out cannot be computed as the simple sum of the respective ultimate bearing and ultimate shearout capacities, which is implicitly permitted in design specifications worldwide. Based on the laboratory test results of 10 hot-rolled steel plate specimens composed of three different grades with nominal thicknesses ranging from 5 to $8 \mathrm{~mm}$, the paper first establishes the ultimate bearing coefficient of a 20-mm bolted connection in a structural steel plate to be 3.5. Coupled with the shear-out equation previously derived, a design equation where the shear-out capacity of the downstream bolt varying quadratically with the end distance is then proposed to determine the combined bearing and shear-out capacity. The proposed equation is demonstrated through verification against independent laboratory test results involving 5-mm plates of three different grades to be significantly more accurate than the simple sum. Explanation for the unexplained results obtained by another researcher using his own equation is provided in this paper.
\end{abstract}

\section{Keywords}

bearing, shear, out, capacity, structural, steel, bolted, connections, combined

Disciplines

Engineering | Science and Technology Studies

\section{Publication Details}

Teh, L. H. \& Uz, M. E. (2016). Combined bearing and shear-out capacity of structural steel bolted connections. Journal of Structural Engineering, Online first 04016098-1-04016098-7. 
4 Abstract:

5 This study is concerned with the strength limit state of serial bolted connections in structural

\section{Combined Bearing and Shear-out Capacity of Structural Steel Bolted}

\section{Connections}

\author{
Lip H. Teh ${ }^{1}$ M.ASCE and Mehmet E. Uz ${ }^{2}$
}

steel plates. It points out that the ultimate load capacity of a serial bolted connection failing in combined bearing and shear-out cannot be computed as the simple sum of the respective ultimate bearing and ultimate shear-out capacities, which is implicitly permitted in design specifications worldwide. Based on the laboratory test results of ten hot-rolled steel plate specimens composed of three different grades with nominal thicknesses ranging from 5 to 8 $\mathrm{mm}$, the paper first establishes the ultimate bearing coefficient of a 20-mm bolted connection in a structural steel plate to be 3.5. Coupled with the shear-out equation previously derived by the authors, a design equation where the shear-out capacity of the downstream bolt varies quadratically with the end distance is then proposed to determine the combined bearing and shear-out capacity. The proposed equation is demonstrated through verification against independent laboratory test results involving 5-mm plates of three different grades to be significantly more accurate than the simple sum. Explanation for the "unexplained" results obtained by another researcher using his own equation is provided in this paper.

Subject headings: bolted connections, structural design, structural steel, thin wall sections Author keywords: bearing strength, connection capacity, shear-out, tear-out

\footnotetext{
${ }^{1}$ Associate Professor, School of Civil, Mining \& Environmental Engineering, University Of Wollongong, Wollongong, NSW 2500, AUSTRALIA.

${ }^{2}$ Lecturer, Department of Civil Engineering, Adnan Menderes University, Aydin, PK:09100, TURKEY. Formerly Associate Research Fellow, ARC Research Hub for Australian Steel Manufacturing, Wollongong, NSW 2500, AUSTRALIA.
} 


\section{Introduction}

22 In the draft 2016 AISC Specifications for Structural Steel Buildings (AISC 2015), the shearout (termed tearout in the draft) failure mode of a bolted connection is treated in separate equations from the bearing failure mode. The former mode is depicted in Figure 1(a), while the latter in Figure 1(b). Photographs of laboratory specimens showing these two distinct failure modes can be found in Teh \& Clements (2012). This treatment marks a departure from previous specifications (AISC 2010), which considered the shear-out failure mode to be a special case of the bearing failure mode. However, other than this formal separation, the equation used to determine the ultimate shear-out capacity remains the same.

In a recent paper, Teh \& Uz (2015a) proposed a design equation to determine the ultimate shear-out capacity of a structural steel bolted connection, where bolt hole deformation at service load is not a concern. The equation was demonstrated through verification against independent laboratory test results around the world to be significantly more accurate than the alternative equations available in design specifications and literature, in particular that found in the current and draft AISC specifications (AISC 2010, 2015).

All the test specimens analysed by Teh \& Uz (2015a), which included serial bolted connections, failed in pure shear-out as the combined bearing and shear-out failure mode was outside their scope. However, in practice, a serial bolted connection may fail in combined bearing and shear-out, depicted in Figure 2, due to the AISC's preference for minimum end distance and bolt pitch as shown on the left-hand side of Figure 3.

It will be pointed out in this paper that the ultimate load capacity of a serial bolted connection failing in combined bearing and shear-out is in general less than the simple sum of the individual bearing and shear-out capacities, even though such a summation procedure is implicitly permitted in the AISC specifications (AISC 2010, 2015) and Eurocode (ECS 
2005). The simple summation procedure is more explicit in the wording of the 1993 specification (AISC 1993), which tacitly assumes a level of ductility that is not generally available for structural steels. A simple summation procedure was also used by Kato (2003).

In the present work, the ultimate load capacity of a bolted connection is defined as its maximum load capacity that is not restricted by concerns regarding the bolt hole deformation at service load. Salih et al. (2011) have stated that the deformation based definition of failure load has led to inconsistency since the failure loads depend on an often arbitrary selection of a limiting deformation. Aalberg \& Larsen (2001) have also commented that the theoretical background to the deformation limit of $6.35 \mathrm{~mm}$ used in the AISC specification is unclear.

In order to determine the design equation that can be reliably used for determining the ultimate load capacity of a serial bolted connection failing in combined bearing and shearout, the ultimate bearing coefficient of a hot-rolled steel bolted connection will be first established through experimental tests in the present work. This step is necessary since the accurate bearing coefficient is uncertain due to the different values provided by design specifications (AISC 2010, ECS 2005, SA 1998), which range from 2.5 to 3.2. Recent test results (Yang et al. 2013) implied a higher bearing coefficient.

Based on the bearing coefficient determined in the present work, and the shear-out equation presented by Teh \& Uz (2015a), a design equation will be proposed for determining the ultimate load capacity of a serial bolted connection meeting the end distance and bolt pitch requirements of the specification (AISC 2010, 2015). The equation will be verified against independent test results where the bolts had not been snug-tightened, since snug-tightening can artificially increase the load capacities of tested bolted connections (Teh \& Yazici 2013).

Following a reviewer's comment, it should be noted that bolted connections in cold-reduced sheet steel (Rogers \& Hancock 2000) is outside the scope of this paper. 


\section{9 Accurate equation for the ultimate shear-out capacity}

Teh \& Uz (2015a) have shown that the ultimate shear-out capacity $P_{\text {so }}$ of a single-bolt structural steel connection is accurately determined from

$$
P_{\text {so }}=1.2 e t F_{u}
$$

in which the active end distance $e$ is defined in Figure $4, t$ is the plate thickness and $F_{\mathrm{u}}$ is the material tensile strength.

Comparisons between Equation (1) and Equation (J3-6d) in the draft specification (AISC 2015), or Equation (J3-6b) in the current specification (AISC 2010), for single-bolted connections failing in shear-out can be made in Table 1. The results of Clause 3.6.1 of Eurocode 3 Part 1.8 (ECS 2005) are also included. The two code equations are shown in Appendix A as Equations (5) and (6), respectively. The variable $P_{\mathrm{t}}$ denotes the ultimate loads obtained by the various researchers in their respective experimental programs. The details of the individual specimen configurations and material properties can be found in Teh \& Uz (2015a). Pursuant to the finding of Teh \& Uz (2015a), specimens composed of very high strength steel with a yield stress equal to or higher than $830 \mathrm{MPa}$ are not included in the table.

It is evident from Table 1 that Equation (1) is considerably more accurate than both code equations. For each of the four test series, both the lowest and the highest professional factors are closest to unity when they are computed using Equation (1). It should be noted that a key factor in the performance of Equation (1) is the use of the active shear length $e$, as opposed to the use of the net shear length $e_{\mathrm{n}}$ in the AISC specification or the gross shear length $e_{1}$ in Eurocode. The use of the correct shear failure planes in Equation (1) in turn enables the use of the well-established shear coefficient of 0.6 for each shear plane (Teh \& Uz 2015b). 
91 Equation (1) will therefore form a basis for determining the ultimate load capacity of a serial

92 bolted connection failing in combined bearing and shear-out. It will also be used in the

93 following section to determine the minimum bolt pitch where the bearing rather than the

94 shear-out failure mode governs.

\section{$95 \quad$ Ultimate bearing coefficients}

96

97

98

99

100

101

102

103

104

105

106

107

108

109

110

111

The bearing capacity $P_{\mathrm{b}}$ of a bolted connection represents the upper bound of its shear-out capacity. It is independent of the end distance (i.e. available shear area), and is most commonly expressed as

$$
P_{b}=C d t F_{u}
$$

in which $C$ is the bearing coefficient and $d$ is the bolt diameter.

According to Equation (J3-6b) of the current and draft specifications (AISC 2010, 2015), the bearing coefficient $C$ is equal to 3.0 when deformation at the bolt hole is not a concern. This coefficient is larger than the maximum value possible specified in Eurocode 3 (ECS 2005), which is equal to 2.5 as evident from Equations (6) and (7) in the appendix. However, the Australian standard (SA 1998) specifies the largest coefficient of all, equal to 3.2.

The authors have not found any published test results that enable the determination of the ultimate bearing coefficient for hot-rolled steel bolted connections. All the specimens tested by Udagawa \& Yamada (1998, 2004), Kim \& Yura (1999), Puthli \& Fleischer (2001), Aalberg \& Larsen (2001, 2002) and Draganic et al. (2014) did not undergo the pure bearing failure mode. The test results at room temperature of Yang et al. (2013) led to a bearing coefficient as high as 3.3, but their conclusion that the "bearing” strength varies linearly with 
112 the end distance up to 4 times the bolt diameter implies an even higher ultimate bearing 113 coefficient.

114 In order to establish the accurate ultimate bearing coefficient for bolted connections in 115 structural steel plates, the authors conducted laboratory tests on the concentrically loaded 116 specimens listed in Table 2. The ratios of ultimate tensile strength to yield stress $F_{\mathrm{u}} / F_{\mathrm{y}}$ of the 117 test materials range from 1.13 to 1.49 , with the nominal plate thickness being either 5 or 8 $118 \mathrm{~mm}$. All the bolts had a nominal diameter of $20 \mathrm{~mm}$, and all the plates were $100 \mathrm{~mm}$ wide. 119 The stroke rate was $2 \mathrm{~mm}$ per minute. An empty cell in the table indicates that the value in the above cell applies.

121 Anticipating that the ultimate bearing coefficient might be as high as 3.5, the required active 122 end distance $e$ for ensuring the bearing failure mode can be found from

$$
1.2 e t F_{u}>3.5 d t F_{u} \Rightarrow e>2.92 d
$$

124 From Equation (3) and Figure 4, it can be determined that the required end distance $e_{1}$ for ensuring the bearing failure mode is equal to 3.17 times the bolt diameter. The nominal end distances $e_{1}$ of the present specimens in Table 2 therefore ranged from 3.5 to 5.0 times the

127 bolt diameter. Figure 5 shows the failed specimens B32_4a and B32_4b soon and well beyond the initiations of bearing fracture, respectively.

129 It can be seen from Table 2 that the resulting bearing coefficients $C_{\mathrm{t}}$ do not vary noticeably with the end distances of the present specimens, and are therefore the ultimate bearing coefficients. The average bearing coefficient of the ten specimens was computed to be 3.49

132 with a standard deviation of 0.13 . 
For the purpose of design, it is proposed that an ultimate bearing coefficient equal to 3.5 is adopted. If this value is used in estimating the bearing capacity of the specimens in Table 2, then the mean professional factor will be 1.00 with a coefficient of variation equal to 0.037 .

In contrast, the AISC and Eurocode bearing coefficients lead to mean professional factors equal to 1.16 and 1.40, respectively. The Eurocode bearing coefficient (ECS 2005) is computed from Equation (6) shown in the appendix, which reduces to 2.5 for all the specimens in Table 2.

\section{Combined bearing and shear-out capacity}

Equation (3) indicates that, if the active end distance $e$ of a downstream bolt is less than 2.92 $d$, which is the case in practice since the required nominal end distances $e_{1}$ only vary from 1.25 to $1.5 d$ (AISC 2010), the shear-out failure mode is more critical than the bearing failure mode for the downstream bolt. On the other hand, since the preferred minimum bolt pitch $p$ is $3 d$ (AISC 2010), the reverse can quite possibly be true for bolts other than the downstream bolt. Therefore, for a serial bolted connection such as that depicted in Figure 3, the governing strength limit state is more likely to be combined bearing and shear-out than pure shear-out or pure bearing (leaving out for the purpose of the present discussion the net section tension fracture mode, which is more likely for serial connections with three or more bolts).

As stated in the Introduction, a simple summation procedure of the individual bearing and shear-out capacities is implicitly permitted in the AISC specifications (AISC 2010, 2015) and Eurocode (ECS 2005) for determining the ultimate capacity of a serial bolted connection failing in combined bearing and shear-out. Such a procedure assumes that either the ultimate bearing and ultimate shear-out limit states of the upstream and downstream bolts are reached concurrently, or the shear-out failure is so ductile that the load sustained by the downstream 
bolt is still close to the ultimate shear-out capacity when the ultimate bearing capacity of the upstream bolt is reached. However, Figure 6 shows that neither condition is true.

The shear-out specimens S32_2b through S32_4a in Figure 6 had the same material and geometric properties as the bearing specimen B32_2b listed in Table 2 except for their nominal end distances, as indicated in Figure 6. It can be seen from the graphs that the ultimate shear-out and bearing failures did not take place at similar deformation levels, and the loads sustained by the shear-out specimens at the deformation level corresponding to the bearing failure were significantly lower than their respective ultimate shear-out loads. Therefore, if the bolt pitch is 3 times the bolt diameter or longer, as preferred by the AISC specification, then the simple sum will be significantly greater than the actual combined capacity since the downstream bolt would sustain a load that is significantly lower than its ultimate shear-out capacity by the time the upstream bolt reaches its own ultimate capacity.

From Equation (3), it can be surmised that if the nominal end distance $e_{1}$ of a downstream bolt failing in shear-out is around $3 d$, then the ultimate shear-out load of the downstream bolt and the ultimate bearing load of the upstream bolt will approach each other. When the end distance reaches the threshold value, the ultimate load capacity of the serial bolted connection is equal to the simple sum of the individual shear-out and bearing capacities.

Based on the preceding discussions and using Equation (1) to determine the individual shearout capacity $P_{\text {so, }}$ it is hypothesised that the ultimate load capacity of a serial bolted connection having the configuration depicted in Figure 3 may be estimated as

$$
P_{p}=k P_{s o}+\left(n_{b}-1\right) P_{b}=\frac{e}{3 d} P_{s o}+\left(n_{b}-1\right) P_{b}=\left\{\frac{e^{2}}{2.5 d}+\left(n_{b}-1\right) 3.5 d\right\} t F_{u}
$$


in which $n_{\mathrm{b}}$ is the total number of bolts in the bolt line. A value of $k$ greater than unity would indicate that the downstream bolt is governed by bearing rather than shear-out failure, and Equation (2) should be used for each bolt with $C=3.5$ as established in the preceding section. The use of " $3 d$ " instead of " $2.92 d$ " in the shear-out term leads to a 3\% error on the safe side.

In practice, a serial connection with $n_{\mathrm{b}}$ equal to three or more will be more likely governed by the net section tension fracture mode than the combined bearing and shear-out mode. For a serial two-bolt connection in which the upstream bolt fails in bearing, Equation (4a) becomes

$$
P_{p}=\left(\min \left[\frac{e^{2}}{2.5 d}, 3.5 d\right]+3.5 d\right) t F_{u}
$$

Equation (4b) ignores the fact that the ultimate load capacity of a serial two-bolt connection may be reached before the upstream bolt fails in bearing. It should also be noted that the equation will not be valid if two similar plates are serially connected to each other in a singlelap joint, as illustrated in Figure 7. In such a case, the ultimate load capacity is equal to twice the shear-out capacity of the downstream bolt. All the specimens analysed in the following section were connected to elements that were much stronger than themselves.

\section{Verifications against laboratory test results}

Equation (4) proposed in this paper for determining the ultimate load capacity of a serial twobolt connection meeting the end distance requirement and bolt pitch preference of the specification (AISC 2010, 2015), depicted in Figure 3, was verified against the test results of Kim \& Yura (1999) and Aalberg \& Larsen (2002). Leaving out the very high strength steel specimens having yield stress equal to or higher than $830 \mathrm{MPa}$, there were 12 "eligible" specimens, as listed in Table 3. The first four in the table were tested by Kim \& Yura (1999), and the rest by Aalberg \& Larsen (2002). 
The specimens tested by Kim \& Yura (1999) had a nominal bolt diameter of $19 \mathrm{~mm}$, while those of Aalberg \& Larsen (2002) had a nominal bolt diameter of $20 \mathrm{~mm}$, giving ratios of bolt pitch to bolt diameter $p / d$ that ranged from 2.95 to 4.05 , as shown in Table 3 . The specimens having $p / d$ of 2.95 were included in the analysis since the ultimate shear-out capacity of the upstream bolt was close to its bearing capacity, and the simple sum of the individual capacities would most likely be over-optimistic. However, the strength of the upstream bolt of such specimens was determined using $1.2 p_{\mathrm{v}}$ instead of $3.5 d$ in Equations (2) and (4b).

Kim \& Yura (1999) were careful to ensure that the applied loads of their test specimens were not transferred by friction through the use of a retaining device instead of a nut. Likewise, Aalberg \& Larsen (2002) only tightened their bolts by hand to ensure that the applied loads were transferred by bearing instead of friction. It may be noted that Puthli \& Fleischer (2001) and Rex \& Easterling (2003), whose results are included in Table 1, also ensured that the bolts were not tightened at all. Avoiding snug-tightening of bolts in an experimental test is important since Teh \& Yazici (2013) have pointed out that snug-tightening of bolts by some researchers led to anomalous ultimate test loads.

Table 3 shows the professional factors $P_{\mathrm{t}} / P_{\mathrm{p}}$ resulting from Equation (4) and from the simple summation of Equations (1) and (2), the latter using the ultimate bearing coefficient $C=3.5$ as determined from the results in Table 2.

It can be seen from Table 3 that Equation (4) is significantly more accurate than the simple sum of the individual shear-out and bearing capacities, which overestimates the ultimate load capacity by $16 \%$ on average $(1 / 0.87=1.16)$. This outcome is consistent with the exposition in the preceding section that the combined bearing and shear-out capacity should be less than the simple sum of the individual capacities. 
The result for specimen AT0530 seems to suggest that Equation (4) can be overoptimistic in certain cases. However, the reported ultimate test load $P_{\mathrm{t}}$ of $122 \mathrm{kN}$ for this specimen appears to be in error for three reasons. First, specimen AT0530 had a similar nominal geometry to specimen BT0530, whose ultimate test load was estimated accurately by Equation (4). It should be noted that the former's material was more ductile than the latter, so lack of ductility could not have explained the result of Equation (4) for specimen AT0530. Second, the reported ultimate test load $P_{\mathrm{t}}$ of $122 \mathrm{kN}$ is even lower than the ultimate bearing strength $P_{\mathrm{b}}$ of the upstream bolt alone, which was computed to be $131.5 \mathrm{kN}$ using $C=3.5$ as established in the section "Ultimate bearing coefficients". Third, the ultimate test load $P_{\mathrm{t}}$ of $122 \mathrm{kN}$ was reported to be exactly the same as the load at the bolt hole deformation of $6.35 \mathrm{~mm}$, in contrast to those of the other specimens for which the difference was as high as $14 \%$.

As shown in Table 2, the use of $C=3.0$ in the AISC's ultimate bearing strength provision (AISC 2010, 2015) led to significant underestimations for all the bearing test specimens. On the other hand, Table 1 shows that the AISC's ultimate shear-out equation, or Equation (5) in the appendix, can lead to significant errors on either side of conservatism. These facts mean that, when the simple summation procedure is used with the AISC equations, it is possible that in some cases the combined conservatism of the individual bearing and shear-out equations offsets the unsafe error of the procedure. Even though the AISC bearing and shearout equations should not ideally be used to determine the combined bearing and shear-out capacity, nor should the simple summation procedure, this possibility was investigated in the present work. Figure 8 plots the professional factors obtained using the current AISC procedure. It can be seen that, despite the potential conservatism afforded by the individual bearing and shear-out equations, the simple summation of the AISC equations still led to overestimations for most specimens. 
The professional factors of Equation (4) are also plotted in Figure 8 for comparisons. It should be noted that the only significant overestimation by this proposed equation is for specimen AT0530, the test result of which appears to be in error as discussed previously.

The box charts in Figure 9 summarise the professional factors of the AISC equations and the authors' own for ultimate pure shear-out, pure bearing and combined bearing and shear-out failures, for a total of 72 specimens that do not include specimen AT0530. The shear-out data encompass those presented by Teh \& Uz (2015a), while the rest can be found in Tables 2 and 3. It can be seen that the authors' equations are significantly more consistent and more accurate than the current AISC equations (AISC 2010, 2015).

\section{Explanation for the results of Kato (2003)}

Kato (2003) proposed a unified system of design equations for bolted connections in flat steel plates that may fail in net section tension fracture, shear-out, block shear or combined block shear and shear-out. He verified his equations against the laboratory test results of Tanuma \& Hashimoto (1991). Kato (2003) identified the test specimens that failed in either net section tension fracture or shear-out.

Kato (2003) found that his system of design equations became increasingly unconservative with increasing ratios of bolt pitch to bolt diameter, which were as high as 10 , as shown in Figure 10. Since the net section tension fracture capacities were not affected by the bolt pitch, it should not be surprising that this outcome applied to the specimens that Kato (2003) believed to have failed in shear-out.

It is clear from Equation (3) that the strength limit state of those specimens, with bolt pitches being considerably greater than the threshold value, were governed by combined bearing and shear-out rather than pure shear-out. The shear-out equation of Kato (2003) would predict 
269

270

271

272

273

275

276

277

278

279

280

281

282

283

increased load capacities with increased bolt pitches, but in reality the ultimate test loads did not increase with increased bolt pitches beyond the threshold value as the upstream bolts invariably failed in bearing. As evident from Equation (2), the bearing capacity is independent of the bolt pitch, unlike the shear-out capacity. It is therefore not surprising that Kato (2003) found that his shear-out equations became increasingly unconservative with increasing ratios of bolt pitch to bolt diameter beyond the threshold value.

Kato (2003) did not provide the individual specimen data of Tanuma \& Hashimoto (1991), and the latter is not accessible to non-Japanese readers. Verification of Equation (4) against the test results of Tanuma \& Hashimoto (1991) has therefore not been carried out.

\section{Conclusions}

This paper has pointed out that, due to the required end distance and preferred bolt pitch prescribed in the AISC specification, a serial bolted connection may fail in combined bearing and shear-out rather than pure shear-out or pure bearing. More importantly, it has explained that the ultimate load capacity of a serial bolted connection failing in combined bearing and shear-out cannot in general be computed as the simple sum of the individual ultimate bearing and ultimate shear-out capacities.

It has also been reiterated that the AISC equation for determining the ultimate shear-out capacity can lead to significant underestimations or overestimations, depending on the end distance. The Eurocode equation, on the other hand, is always overconservative and excessively so for almost all specimens. The ultimate shear-out capacities of all the specimens can be estimated quite accurately using the equation previously proposed by the authors. This shear-out equation forms a basis for determining the ultimate load capacity of a serial bolted connection failing in combined bearing and shear-out. 
292

293

294

295

296

297

298

299

300

301

302

303

304

305

306

307

308

309

310

311

312

313

314

The ultimate bearing coefficients assumed in the major steel design specifications range from 2.5 to 3.2. However, the present test results involving $20-\mathrm{mm}$ bolts in 5 or $8 \mathrm{~mm}$ plates of three different grades suggest that the more accurate coefficient is 3.5. This coefficient is used in the proposed equation for determining the ultimate load capacity of a serial bolted connection failing in combined bearing and shear-out.

The proposed equation takes into account the fact that the downstream bolt sustains a load that may be significantly lower than its ultimate shear-out capacity when the upstream bolt reaches or approaches the latter's own ultimate bearing capacity. It assumes a contribution from the downstream bolt that varies quadratically with its end distance (up to the bearing failure). The new equation was verified against independent laboratory test results where the bolts had not been snug-tightened, involving plates of three different grades with a nominal thickness of $5 \mathrm{~mm}$. The proposed equation was found to be significantly more accurate than the simple summation procedure permitted by the design specifications.

Overall, the box charts show that the equations proposed by the authors are more consistent and more accurate than the current AISC equations for determining the ultimate load capacities of bolted connections failing in pure shear-out, pure bearing or combined bearing and shear-out. Bolt hole deformation at service load is not a concern in the present work.

\section{Acknowledgments}

The authors would like to thank the Australian Research Council for funding this research through the ARC Research Hub for Australian Steel Manufacturing under the Industrial Transformation Research Hubs scheme (Project ID: IH130100017). The authors would also like to thank Chris Killmore, Product Innovation Specialist, Bluescope Australia and New Zealand, for supplying the steel materials used in the present work. The specimens were 
315 fabricated by Ritchie McLean and tested by Duncan Best, some of which with the assistance

316 of Jake Fitch and Melissa-Paige Cooper, two honours thesis students at the University of

317 Wollongong.

\section{References}

319 Aalberg, A. and Larsen, P. K. (2001) "Bearing strength of bolted connections in high strength steel.” Proc. $9^{\text {th }}$ Nordic Steel Construction Conf., Helsinki, Finland, 859-866.

Aalberg, A. and Larsen, P. K. (2002) "The effect of steel strength and ductility on bearing failure of bolted connections.” Proc. $3^{\text {rd }}$ European Conf. Steel Structures, Coimbra, Portugal, 869-878.

AISC (1993) Load and Resistance Factor Design Specification for Structural Steel Buildings, American Institute of Steel Construction, Chicago IL.

AISC (2010) Specification for Structural Steel Buildings, ANSI/AISC 360-10, American Institute of Steel Construction, Chicago IL.

AISC (2015) Specification for Structural Steel Buildings, Public Review Draft March 2015, American Institute of Steel Construction, Chicago IL.

Draganic, H., Doksanovic, T., and Markulak, D. (2014) "Investigation of bearing failure in steel single bolt lap connections.” J. Construct. Steel Res., 98, 59-72.

ECS (2005) Eurocode 3: Design of steel structures, Part 1.8: Design of joints, EN 1993-1-8, European Committee for Standardisation, Brussels, Belgium.

Kato, B. (2003) "Unified strength evaluation of bolted joints." Int. J. Steel Struct., 3, 137144.

Kim, H. J., and Yura, J. A. (1999) "The effect of ultimate-to-yield ratio on the bearing strength of bolted connections.” J. Construct. Steel Res., 49 (3), 255-269. 
Puthli, R. and Fleischer, O. (2001), "Investigations on bolted connections for high strength steel members.” J. Construct. Steel Res., 57 (3), 313-326.

Rex, C. O. and Easterling, W. S. (2003) "Behavior and modelling of a bolt bearing on a single plate.” J. Struct. Eng., 129 (6), 792-800.

Rogers, C. A., and Hancock, G. J. (2000) "Failure modes of bolted-sheet-steel connections loaded in shear.” J. Struct. Eng., 126 (3), 288-296.

Salih, E. L., Gardner, L., and Nethercot, D. A. (2011) "Bearing failure in stainless steel bolted connections.” Eng. Struct., 33 (2), 549-562.

SA (1998). Steel Structures, AS 4100-1998, Standards Australia.

Tanuma, Y., and Hashimoto, K. (1991) "Research on the strength of steel gusset plates subjected to tension.” AIJ J. Struct. Eng., 37B, 263-274.

Teh, L. H., and Clements, D. D. A. (2012) "Block shear capacity of bolted connections in cold-reduced steel sheets.” J. Struct. Eng., 138 (4), 459-467.

Teh, L. H. and Uz, M. E. (2015a) "Ultimate shear-out capacity of structural steel bolted connections.” J. Struct. Eng., 141 (6), 04014152.

Teh, L. H., and Uz, M. E. (2015b) "Block shear failure planes of bolted connections Direct experimental verifications.” J. Construct. Steel Research, 111, 70-74.

Teh, L. H., and Yazici, V. (2013) "Shear lag and eccentricity effects of bolted connections in cold-formed steel sections.” Eng. Struct., 52, 536-544.

Udagawa, K. and Yamada, T. (1998) "Failure modes and ultimate tensile strength of steel plates jointed with high strength bolts.” J. Struct. Construct. Eng. AIJ, 505, 115-122.

Udagawa, K. and Yamada, T. (2004) "Ultimate strength and failure modes of tension channels jointed with high strength bolts." Proc. $13^{\text {th }}$ World Conf. Earthquake Engineering, Vancouver, BC, Paper No. 3288. 
362 Yang, K. C., Hsu, R. J., and Hsu, C. F. (2013) "Effect of end distance and bolt number on 363 bearing strength of bolted connections at elevated temperature.” Int. J. Steel Struct., 13 $364 \quad(4), 635-644$. 
365 Appendix A. Code equations for the ultimate shear-out capacity

366 Equations (J3-6b) and (J3-6d) in the current and draft AISC specifications (AISC 2010,

367 2015), respectively, specify the ultimate shear-out capacity $P_{\text {so }}$ of a single-bolt connection to 368 be

369

$$
P_{s o}=1.5 e_{n} t F_{u}
$$

370 in which the variable $e_{\mathrm{n}}$ is the clear end distance defined in Figure 4.

371 For all the single-bolt specimens analysed in this paper, Clause 3.6.1 of Eurocode 3 Part 1.8

372 (ECS 2005) determines the strength limit load from

373

$$
P_{s o}=\min \left(\frac{e_{1}}{3 d_{h}}, 1.0\right) 2.5 d t F_{u}
$$

374 in which the nominal end distance $e_{1}$ is defined in Figure 4, and $d_{\mathrm{h}}$ is the bolt hole diameter.

375 As in the current AISC specification (AISC 2010), Eurocode 3 (ECS 2005) treats the shear-

376 out failure mode as a special case of the bearing failure mode. The Eurocode's ultimate

377 bearing coefficient is therefore equal to 2.5, when the end distance is at least 3 times the bolt

378 hole diameter, or the bolt pitch is at least 3.75 times the bolt hole diameter.

379 For an upstream bolt in a serial bolted connection, Eurocode 3 computes the bearing 380 coefficient as

381

$$
C=\min \left(\frac{p}{3 d_{h}}-\frac{1}{4}, 1.0\right) 2.5
$$




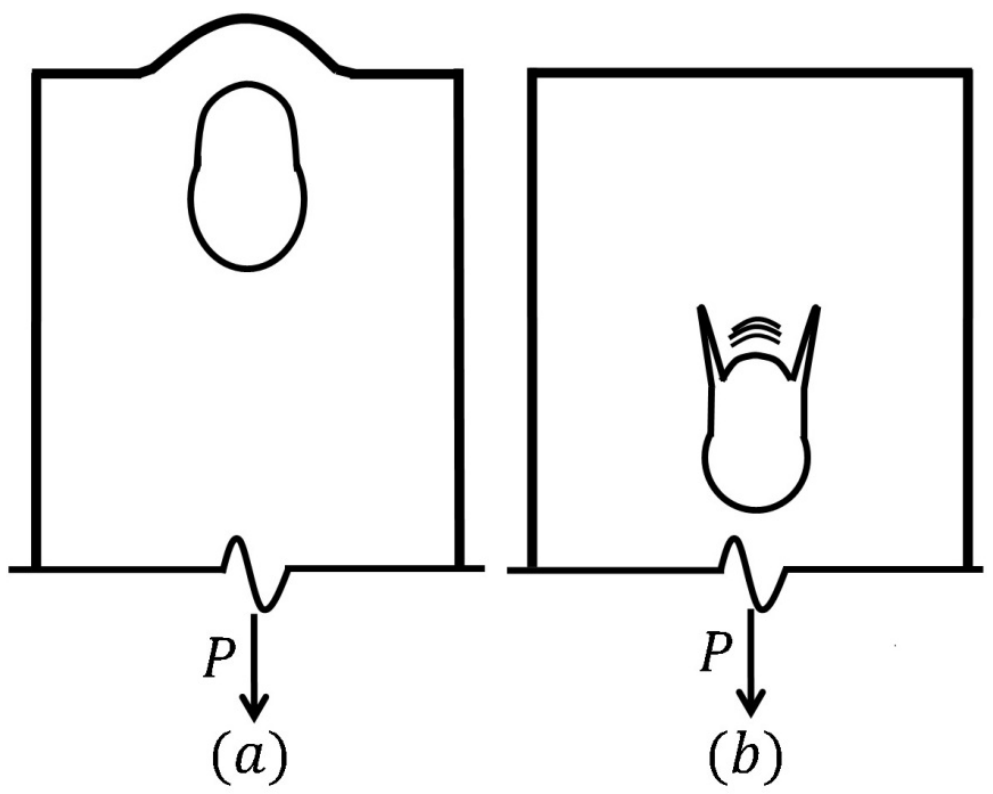

Figure 1 Two distinct failure modes: (a) Shear-out (or tearout); (b) Bearing 


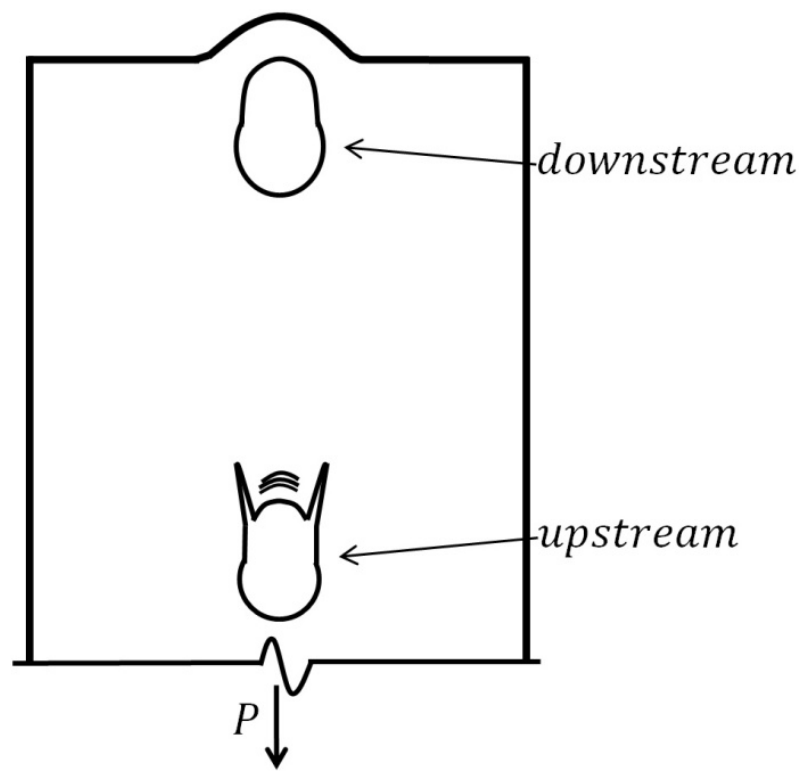

Figure 2 Serial bolted connection subjected to the combined bearing and shear-out mode 


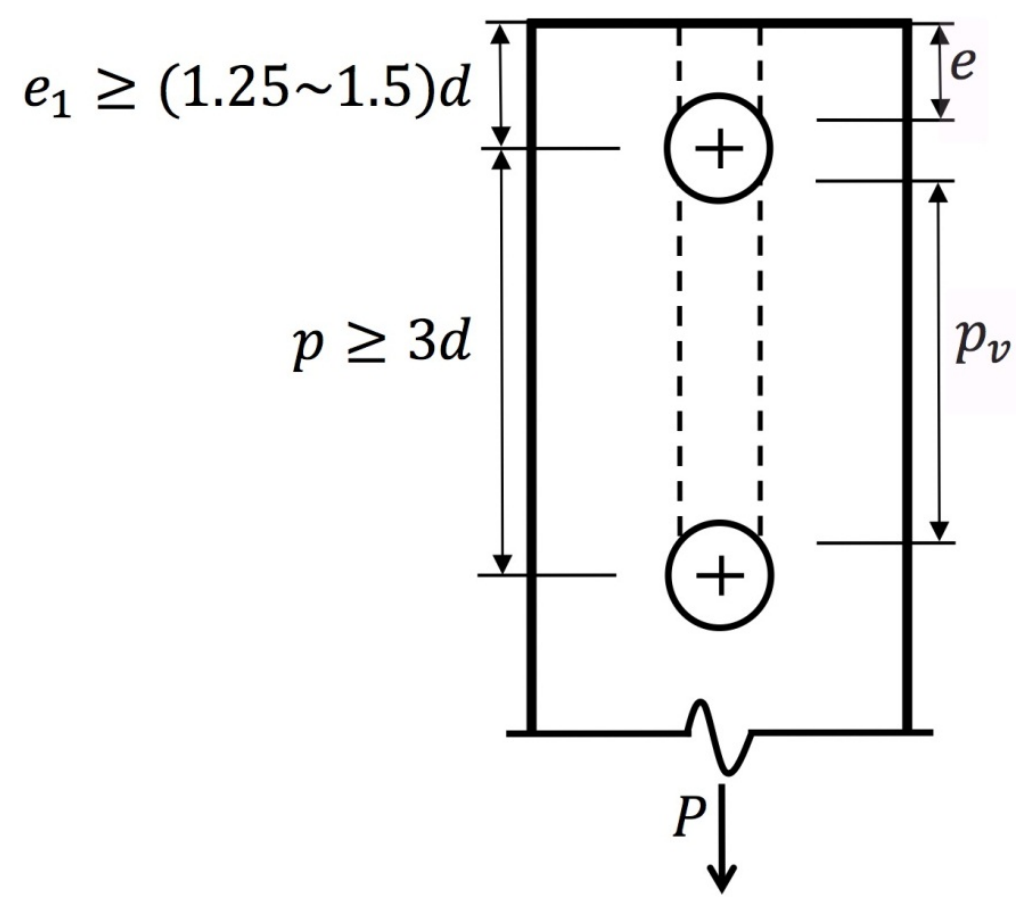

Figure 3 Required and preferred distances according to the specification (AISC 2010) 


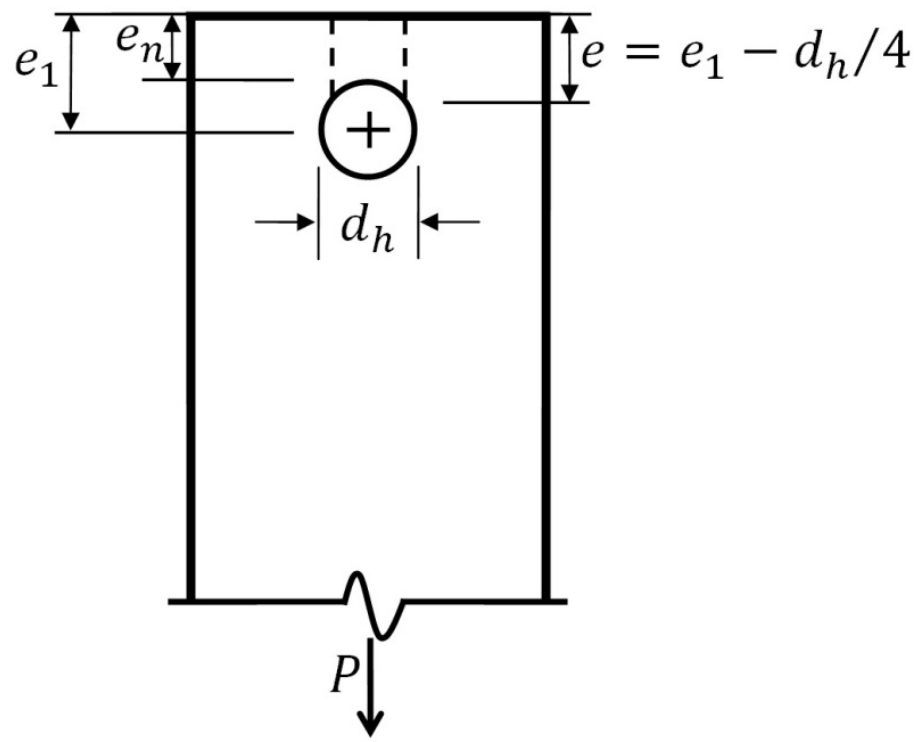

Figure 4 A single-bolt connection 

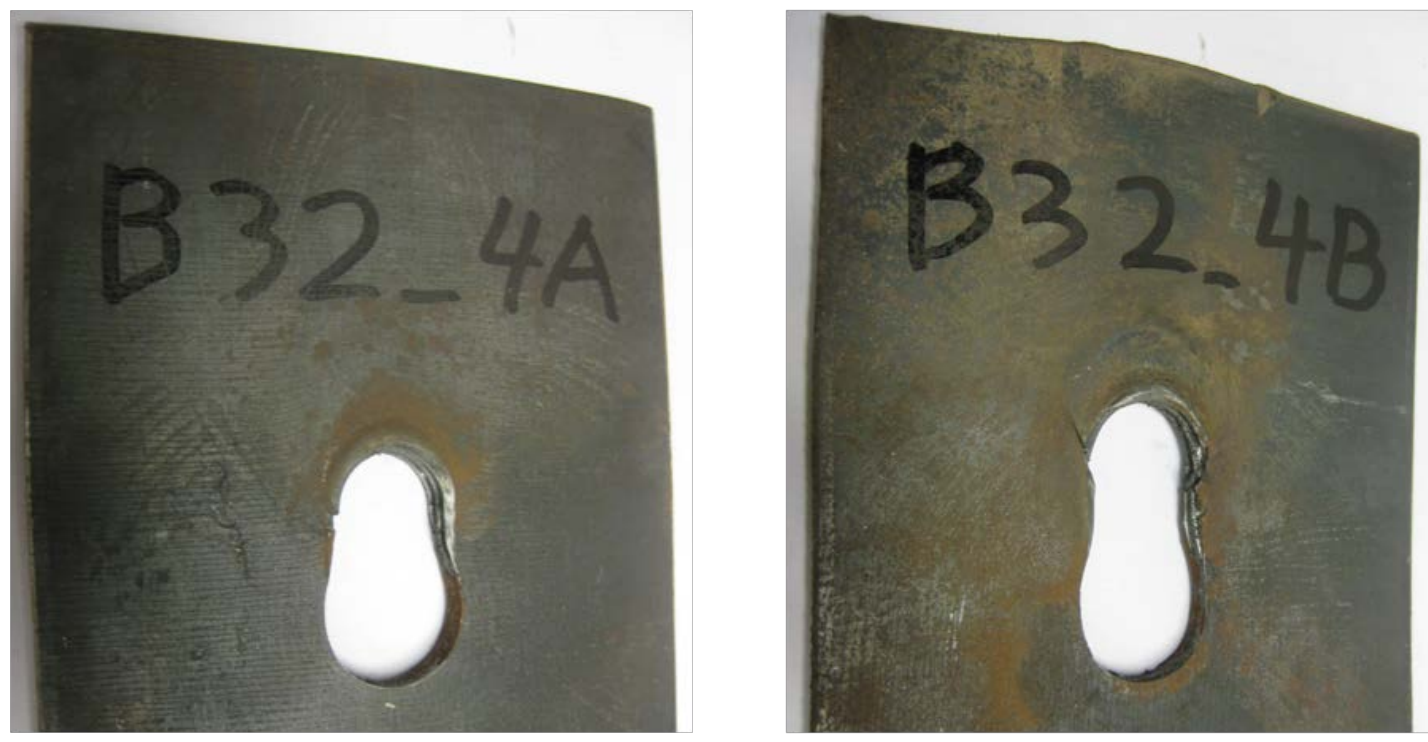

Figure 5 Failed specimens soon and well beyond the initiations of bearing fracture 


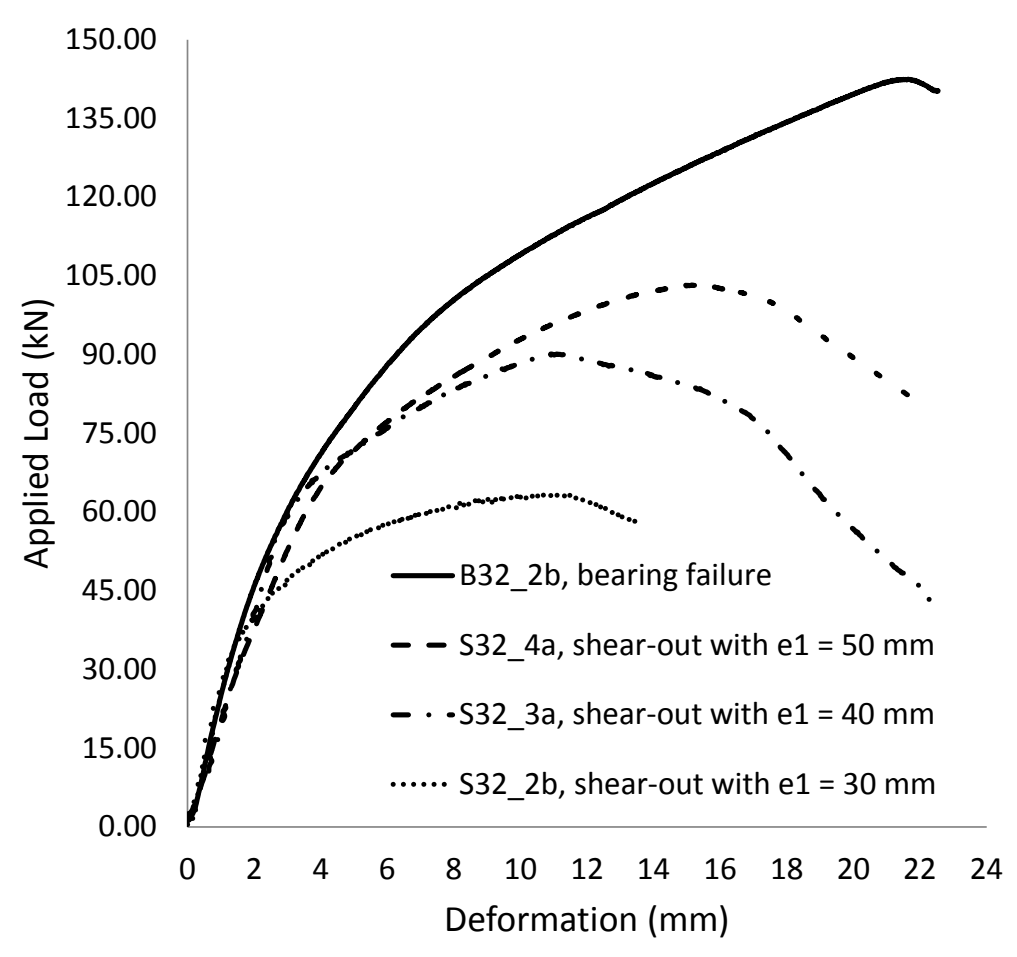

Figure 6 Deformation capacities of bolted connections failing in shear-out and bearing 


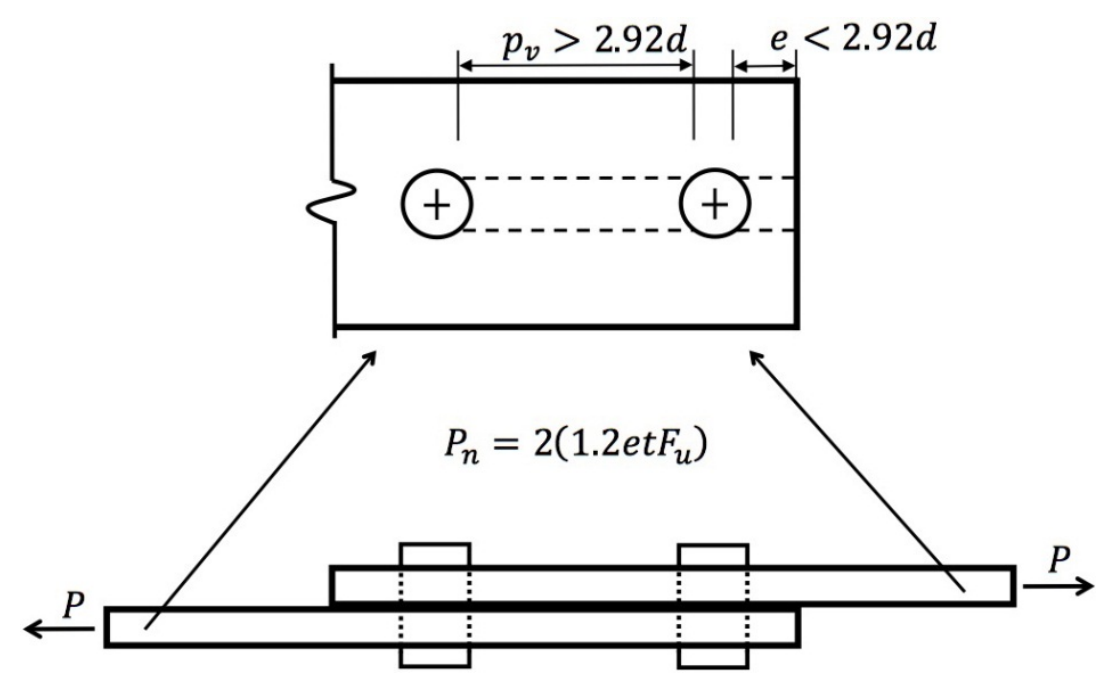

Figure 7 Configuration controlled by the shear-out failures of downstream bolts 


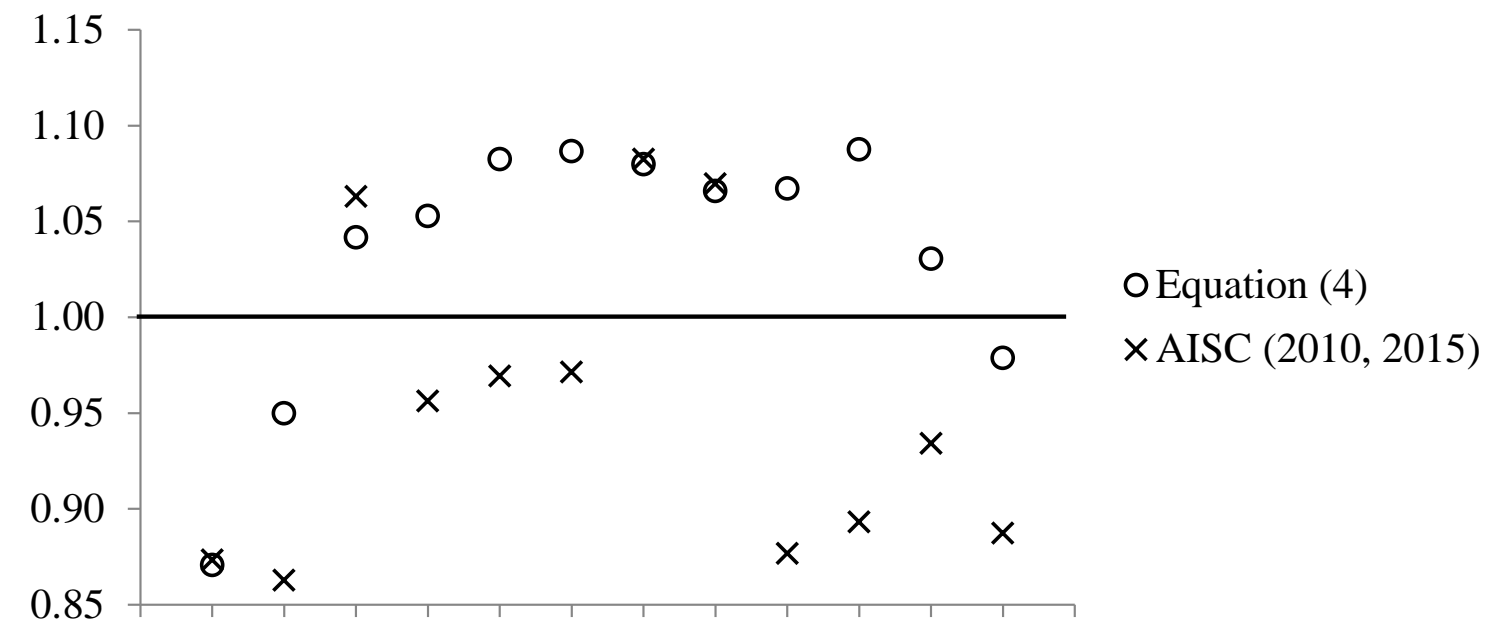

Figure 8 Professional factors for specimens failing in combined bearing and shear-out 


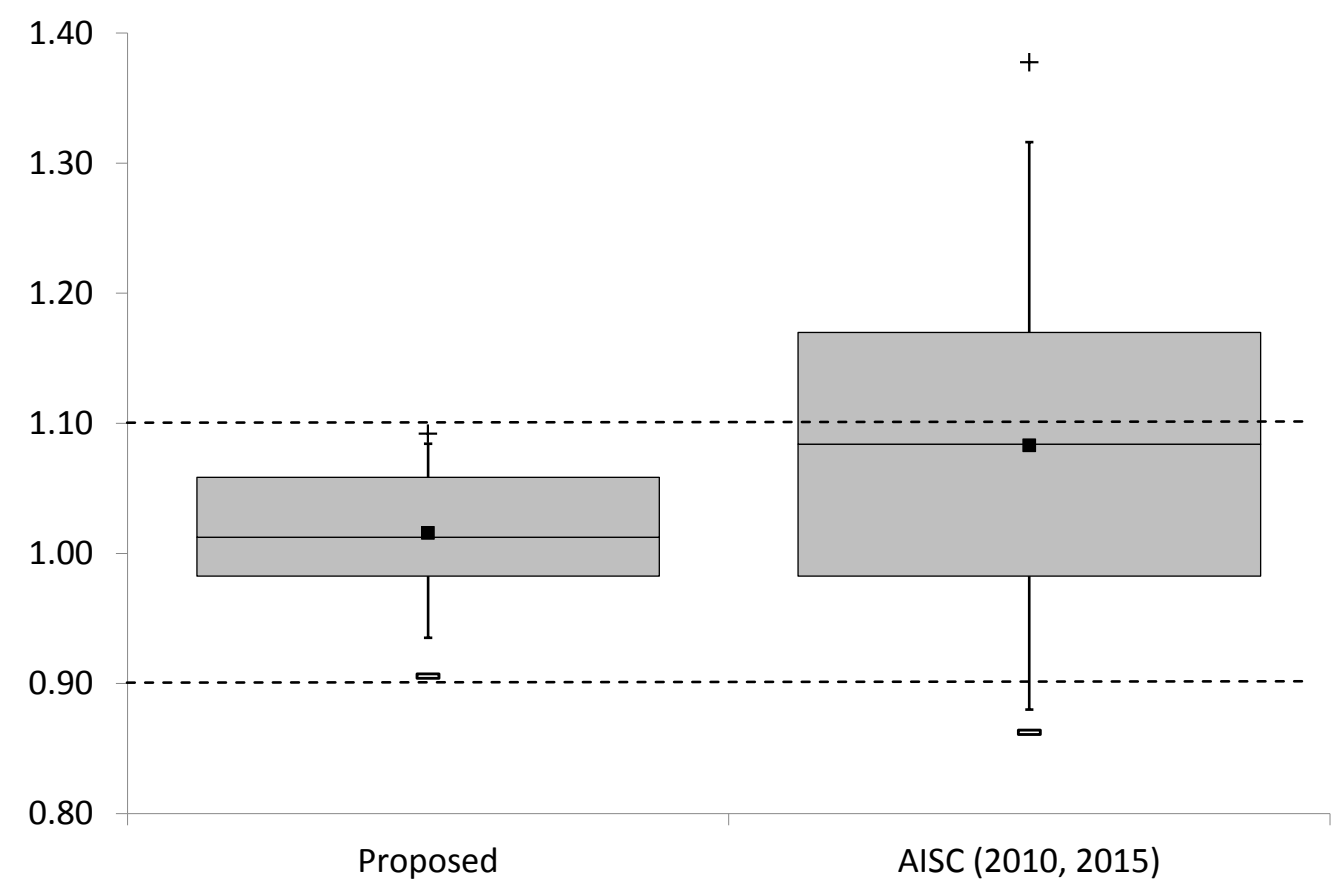

Figure 9 Overall professional factors of proposed and AISC equations 


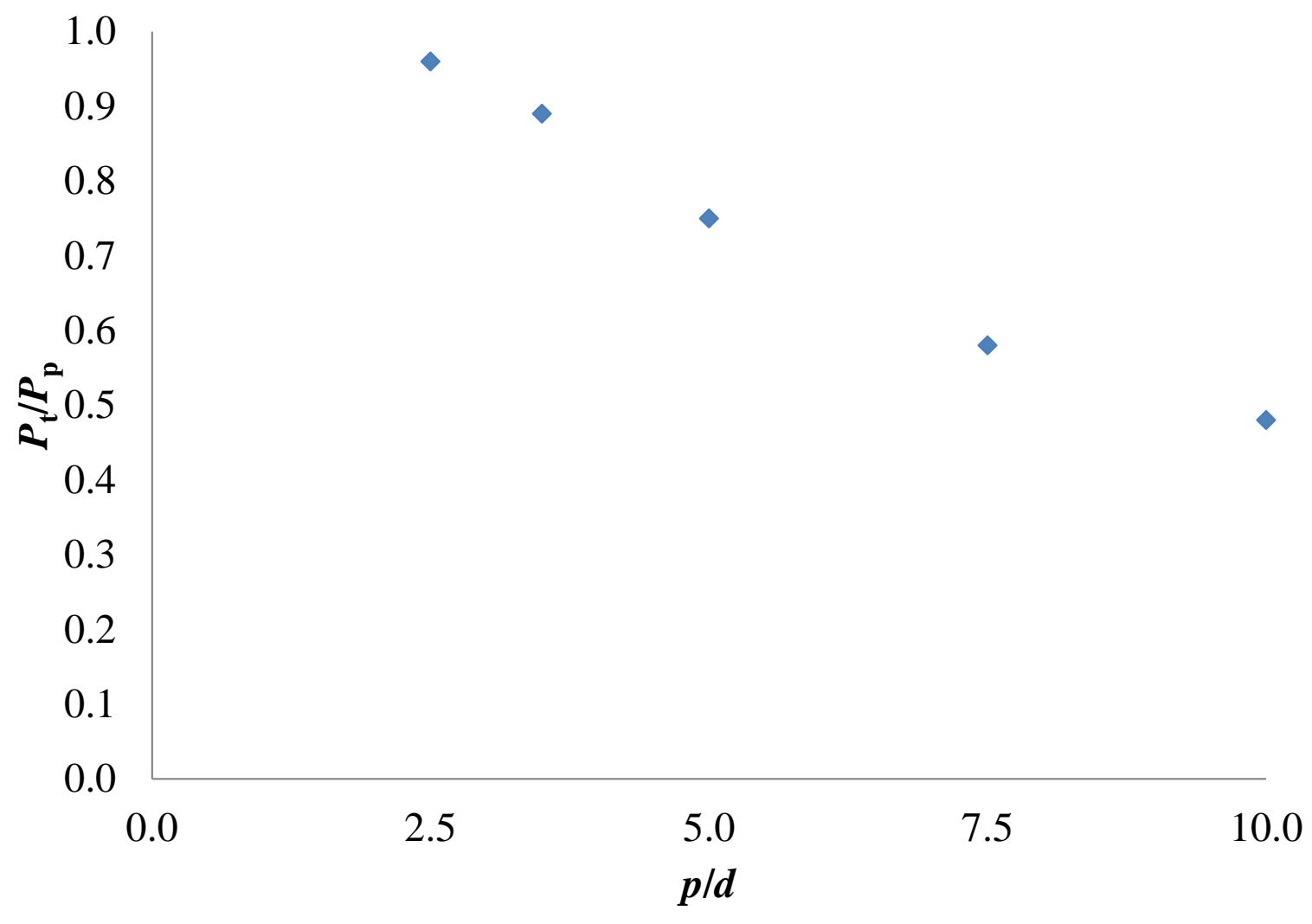

Figure 10 Results of Kato (2003) for Tanuma \& Hashimoto (1991) 